\title{
No evidence for an inbreeding avoidance system in the bumble bee Bombus terrestris
}

\author{
Gherardo Bogo ${ }^{1,2}$, Natasha de MANINCOR ${ }^{2,3}$, Alessandro FisogNI ${ }^{2}$, Marta GALlonI ${ }^{2}$, \\ Laura ZAVATTA $^{2}$, Laura BoRTOLOTTI ${ }^{1}$ \\ ${ }^{1}$ Consiglio per la ricerca in agricoltura e l'analisi dell'economia agraria, Centro di ricerca agricoltura e ambiente (CREA-AA), \\ Via di Saliceto 80, 40128, Bologna, Italy \\ ${ }^{2}$ Dipartimento di Scienze Biologiche, Geologiche e Ambientali, Università di Bologna, Via Irnerio 42, 40126, Bologna, \\ Italy \\ ${ }^{3}$ Univ. Lille, CNRS, UMR 8198 - Evo-Eco-Paleo, F-59000, Lille, France
}

Received 5 September 2017 - Revised 30 January 2018 - Accepted 20 March 2018

\begin{abstract}
Inbreeding is caused by the mating of closely related individuals and may produce a decrease in the fitness of offspring and have deleterious consequences for adults. In haplodiploid social Hymenoptera inbreeding has a further negative effect due to the production of unviable or sterile diploid males. As a consequence, mechanisms of inbreeding avoidance would be expected to evolve. In this study, we investigated the mating choice between related (inbred) or unrelated (outbred) gynes and males of Bombus terrestris reared in laboratory conditions by performing cage and tunnel experiments. Not only did we find no mating preference for related or unrelated partners (mating success $41.55 \pm 3.7$ and $39.69 \pm 4.4 \%$, respectively), but the mating latency was even shorter in inbred $(6.97 \pm 0.6 \mathrm{~min})$ than in outbred matings $(8.74 \pm 0.8 \mathrm{~min})$. We hypothesize that in wild populations of $B$. terrestris, the lack of incest avoidance could be compensated by tolerance of high levels of inbreeding.
\end{abstract}

\section{Bombus terrestris / inbreeding / incest avoidance / kin recognition / mating preference}

\section{INTRODUCTION}

In animal populations, inbreeding is caused by the mating of closely related individuals and may trigger the phenomenon of inbreeding depression, characterized by increased homozygosity and the consequent expression of deleterious recessive alleles (Charlesworth and Charlesworth 1987; Barrett and Charlesworth 1991; Lacy et al. 1993; Charlesworth and Willis 2009). In haplodiploid hymenopterans, inbreeding has further negative consequences due to their particular mechanism of sex determination, which follows the singlelocus complementary sex determination system

Corresponding author: G. Bogo,

gherardo.bogo2@unibo.it

Manuscript editor: James Nieh
(sl-CSD) (Van Van Wilgenburg et al. 2006). In social species, as a result of inbred mating, there is a variable probability, depending on the kinship, that queens share one of the two alleles for the sex-determining locus with males (e.g., $50 \%$ of probability in sibling matings). When a sibling mating occurs between brother and sister sharing the same sex allele, $50 \%$ of the fertilized eggs result homozygous at the sex-determining locus and develop into unviable or sterile diploid males (Ross and Fletcher 1986; Liebert et al. 2004; Whitehorn et al. 2009a). In the case of nephewniece matings, the percentage of diploid males in the progeny is $37.5 \%$ (Duchateau et al. 1994), while in nephew-aunt matings it reaches $75 \%$ (Gosterit 2016).

Studies on wild populations of bumble bees showed that many species suffer from the consequences of inbreeding, mostly due to geographic 
isolation and small population size (Darvill et al. 2006; Ellis et al. 2006; Whitehorn et al. 2011; Darvill et al. 2012). The costs associated with inbreeding in bumble bee populations would suggest the evolution of inbreeding avoidance mechanisms. Polyandry, social recognition, and dispersal of individuals from their natal group are among the most common and efficient systems to avoid inbreeding in social insects (Pusey and Wolf 1996; Tabadkani et al. 2012), but they are only clearly represented in a few bumble bee species. Only a few bumble bee species show polyandry (e.g., Bombus hypnorum, B. bifarius, B. californicus, $B$. frigidus, $B$. huntii, and $B$. rufocinctus ), while most of them are monandrous (Estoup et al. 1995; Schmid-Hempel and Schmid-Hempel 2000; Brown et al. 2002). The mechanism of incest avoidance through kin recognition has been described in several social hymenoptera, such as Apis mellifera (Getz and Smith 1986), some species of halictine bees (Buckle and Greenberg 1981; Smith and Ayasse 1987), polistine wasps (Gamboa et al. 1986; Liebert et al. 2010), and several species of ants (Keller and Passera 1993; Keller and Ross 1998). The role of kin recognition in inbreeding avoidance has been studied in a few bumble bee species. Foster (1992) observed the presence of nestmate recognition and mating avoidance in $B$. frigidus and $B$. bifarius but not in $B$. californicus and $B$. rufocinctus. Whitehorn et al. (2009b) observed a longer mating latency between siblings compared to non-siblings in gynes and males of Bombus terrestris, and interpreted it as evidence for kin recognition for inbreeding avoidance. Despite this, inbred mating occurred anyway.

Mate recognition in bumble bees passes through both behavioral and chemical features (Baer 2003; Ayasse and Jarau 2014). Male bumble bees of different species can display four kind of pre-copulatory sexual behaviors to find and attract females: perching, territoriality, nest surveillance, and scent-marking and patrolling (Brown and Baer 2005; Goulson 2010). B . terrestris males display scent-marking and patrolling as pre-copulatory sexual behavior to find and attract females (Brown and Baer 2005; Goulson 2010). This is the most common mating location mechanism in bumble bees and consists in males patrolling along paths where they scent-mark objects to attract gynes (Ayasse and Jarau 2014). In addition, males of $B$. terrestris may have a very broad mating range (up to $9.9 \mathrm{~km}$; Kraus et al. 2009), which could also contribute to avoiding inbreeding.

$B$. terrestris is one of the most widespread and abundant bumble bee species in the West Palaearctic region (Rasmont et al. 2008) and queens of this species are monandrous (SchmidHempel and Schmid-Hempel 2000). However, the above-mentioned behavior of male patrolling cannot be observed in small experimental flight cages (Djegham et al. 1994; Sauter and Brown 2001). Previous studies showed that mating success in confinement can be influenced by several factors, such as temperature, photoperiod, adult age and size, male dimension, and experience (Tasei et al. 1998; Kwon et al. 2006; Amin et al. 2007; Amin et al. 2010; Amin et al. 2012; Gosterit and Gurel 2016). Evidence indicates that wild populations of $B$. terrestris can tolerate high levels of inbreeding, since they are able to spread as an invasive species originating from few adult individuals (Schmid-Hempel et al. 2007). In addition, inbreeding does not seem to negatively affect the immune response of adults in confined conditions (Gerloff et al. 2003). Although some studies on captive colonies of $B$. terrestris demonstrated that inbreeding can affect colony initiation and colony growth (Gosterit 2016), and that less workers and males were produced after some generations of inbreeding (Beekman et al. 1999), in other studies inbred colonies grew at similar rates or performed even better than outbred colonies, despite the production of diploid males (Duchateau et al. 1994; Gerloff and SchmidHempel 2005).

In this study, we compared the mating occurrence, mating latency, and copulation duration between related and unrelated bumble bee gynes and males under experimental conditions not tested previously. Our aim was to verify whether a mating preference toward the unrelated partner exists as a mechanism to avoid incest in $B$. terrestris. When such a mechanism could be demonstrated, this would facilitate mating procedures in the artificial breeding of bumble bees, avoiding the checking of the parental origin of mating pairs. 


\section{METHODS}

\subsection{Study species and rearing conditions}

Second-generation laboratory colonies of $B$. terrestris $(n=25)$ were reared from commercial colonies (Bioplanet srl, Cesena, Italia) following Bogo et al. (2017). Subsequently, during the phase of male and gyne production, the obtained colonies were maintained at $25 \pm 1{ }^{\circ} \mathrm{C}$ and $60 \pm 10 \%$ relative humidity $(\mathrm{RH})$, in continuous darkness, and fed ad libitum with fresh frozen pollen and sugar syrup. We daily removed newly emerged gynes and males and we put them in separate plastic boxes of $25 \times 15 \times 14 \mathrm{~cm}^{3}$ (up to 20 in the same box), according to their gender, date of emergence, and colony of origin. We obtained a total of 2215 gynes and 3550 males. Gynes and males were kept in the same climatic room of the colonies, and fed ad libitum with fresh frozen pollen and sucrose syrup until they were used for the mating experiment or discarded.

\subsection{Mating tests design}

For the mating tests, we used 1-10-day-old gynes and 5-25-day-old males, since these are the respective age ranges at which they meet sexual maturity (Tasei et al. 1998; Amin et al. 2012). In order to obtain a sufficient number of sexuals, we did not choose only the optimal mating ages, namely 7 days for queens and 12 days for males (Duchateau and Marien 1995; Duvoisin et al. 1999), instead we included the entire period of sexual maturity, which in our experience was suitable for mating. We used a total of 517 gynes and 1115 males sampled from gynes and males produced by the second-generation colonies (Online Resource 1). We avoided to mate gynes and males derived by colonies originated by sister queens but we cannot exclude that founder queens were related in some way (e.g., they derived from a common family line in the commercial breeding). When possible, we selected medium- to large-sized gynes and males (visual estimation) and we always avoided using small males, since in $B$. terrestris the size of males has a positive impact on mating success (Amin et al. 2012). Bumble bees were sampled from the colonies, marked on the thorax with a color tag according to the colony of origin, and placed in groups with a gyne:male ratio of $1: 2$, to assure a higher mating propensity (Kwon et al. 2006; Amin et al. 2010). The total number of individuals in the groups ranged between 12 and 62, according to the number of gynes and males of the proper age interval present at the same time in the same colonies.

We conducted two different mating tests: in the first ("type 1"), gynes belonged to only one colony; in the other ("type 2"), gynes belonged to two different colonies. Even though the final mating choice should rely on queens (Whitehorn et al. 2009b), we included the "type 2 " test to account for possible choices made by males. For each mating type, we added both related " $R$ " (i.e., belonging to the same colony) and unrelated "U" (i.e., from a different colony) males to test the mating preference based on the relationship (Figure 1). In each mating session, the gyne:male ratio was 1:2.

Each mating test was performed in two different environmental conditions: (i) inside a wooden flying cage $\left(40 \times 40 \times 75 \mathrm{~cm}^{3}\right)$ with mesh walls; (ii) inside a net tunnel $\left(4 \times 2 \times 2 \mathrm{~m}^{3}\right)$ in more natural conditions (Bergman and Bergström 1997). In both cases, we furnished fresh frozen pollen and sucrose syrup for the whole test duration. Cage tests were carried out in a climate room, maintained at $20 \pm 1{ }^{\circ} \mathrm{C}$ and $55 \pm 5 \% \mathrm{RH}$ (following Amin et al. 2010), in natural daylight. Tunnel tests were conducted outdoors, at a temperature of $26-29{ }^{\circ} \mathrm{C}$ and $\mathrm{RH}$ of $50-70 \%$. We performed a total of 47 mating sessions: 28 of type 1 (17 in cage and 11 in tunnel) and 19 of type 2 (10 in cage and 9 in tunnel).

\subsection{Response measures}

Mating sessions started when gynes and males were released together in the cage or tunnel, and they were terminated after $1 \mathrm{~h}$, irrespective of the mating success. For the whole duration of the test, we constantly observed individuals and recorded the precise moment when copulation began, in order to calculate mating latency (namely the time elapsed between the start of the mating session and the start of copulation). As soon as mating began, each mating pair was removed from the cage or tunnel and transferred to an individual 


\section{Type 1}

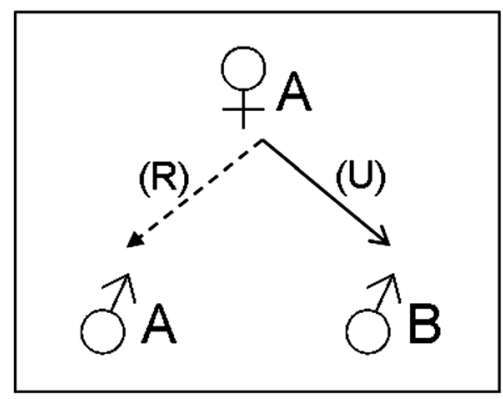

Type 2

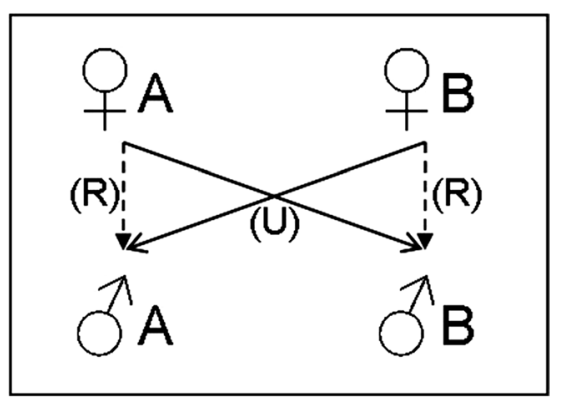

Figure 1. Test design of the two types of mating. The subscript letters (A and $\mathrm{B}$ ) indicate the bumble bees provenience from the same or from different colonies. $R$ related, $U$ unrelated.

transparent plastic box $\left(12 \times 9 \times 9 \mathrm{~cm}^{3}\right)$, where it was constantly observed to record the moment of copulation ended, in order to calculate copulation duration. For each couple, we recorded the colony of origin of the gyne and male, and whether they were related or unrelated. For each mating session, we also calculated the mating rate as the number of mating pairs on the number of gynes that entered the session.

\subsection{Data analysis}

Data were firstly tested for normality (ShapiroWilk test). When data were not normally distributed, we used non-parametric statistical tests. Proportions were transformed using arcsine-squareroot. Differences in mating rates, timing of mating latency, and copulation duration between the two environments (cage and tunnel), the two types of mating (type 1 and type 2), and between related and unrelated bumble bees were analyzed with three-way ANOVA followed by Tukey post-hoc test. The influence of the maternal colony of gynes and males on mating success and in partner choice was tested using the non-parametric Kruskal-Wallis $H$ test. Statistical analyses were performed with STATISTICA software. Power of statistical tests was analyzed with post-hoc power analysis (conventional small, medium, and large effect sizes set at $f=0.1, f=0.25$, and $f=0.4$, respectively) using $\mathrm{G}^{*}$ Power 3.0 software. Power values greater than 0.8 indicated adequate power (Williams et al. 2001). Data are shown as mean $\pm \mathrm{SE}$.

\section{RESULTS}

\subsection{Mating rates and partner preference}

Without considering the relationship (i.e., related or unrelated) between gynes and males, we obtained a total mean mating rate of $82.2 \pm 0.02 \%$ (number of matings $=409$ ), ranging from $73.1 \pm$ $4.33 \%$ (number of matings $=95$ ) in the tunnel with mating type 2 to $86.6 \pm 3.25 \%$ (number of matings $=107$ ) in the cage with mating type 1 .

Factors "Environment," "Type," and "Relationship" and the pairwise interactions of these three factors had no significant effect on the mating rates, but there was a significant effect in the interaction among the three factors together (Table I, Figure 2).

Post-hoc power analysis showed that the statistical test was able to detect only large effects $(f=$ 0.01 , calculated power $=0.15 ; f=0.25$, calculated power $=0.63 ; f=0.4$, calculated power $=0.96$ ).

\subsection{Measurement of mating phases}

The three-way ANOVA showed that factors "Environment" (tunnel = $12.10 \pm 0.817 \mathrm{~min}$; cage $=3.83 \pm 0.413 \mathrm{~min}$ ), "Relationship" (unrelated = $8.74 \pm 0.746 \mathrm{~min}$; related $=6.97 \pm 0.644 \mathrm{~min}$ ), and their interaction had a significant effect on the 
Table I. Three-way ANOVA table of the effects of "Environment" (cage or tunnel), "Type" (I or II), and "Relationship" (related or unrelated) on mating rate

\begin{tabular}{llll}
\hline & df & $F$ & $P$ \\
\hline Environment & 1,86 & 2.446 & 0.122 \\
Type & 1,86 & 0.287 & 0.593 \\
Relationship & 1,86 & 0.375 & 0.542 \\
Environment*Type & 1,86 & 0.091 & 0.763 \\
Environment*Relationship & 1,86 & 0.140 & 0.710 \\
Type*Relationship & 1,86 & 0.084 & 0.773 \\
Environment*Type*Relationship & 1,86 & 6.972 & 0.010 \\
\hline
\end{tabular}

mating latency, while the factor "Type," its interaction with "Environment" and "Relationship," and the three factors together had no effect on mating latency (Table II, Figure 3).

The same analysis on the mating duration showed that factors "Environment" (tunnel = $21.79 \pm 0.509 \mathrm{~min} ;$ cage $=31.15 \pm 0.512 \mathrm{~min})$, "Type" (type $1=25.50 \pm 0.543 \mathrm{~min}$; type $2=$ $27.90 \pm 0.662 \mathrm{~min}$ ), and the interaction among the three factors had a significant effect on the mating duration, while the factor "Relationship" and the pair wise interactions of the three factors had no effect on this parameter (Table III, Figure 4).

Post-hoc power analysis showed that both statistical tests were not able to detect small effects $(f=0.01$, calculated power $=0.51 ; f=$ 0.25 , calculated power $=0.99 ; f=0.4$, calculated power $=1$ ).

\subsection{Effect of the maternal colony}

The maternal colony of gynes did not influence either the mating success $\left(H_{22}=32.20, P=0.074\right)$ or the partner choice $\left(H_{22}=32.17, P=0.075\right)$. The maternal colony of males influenced the mating success $\left(H_{24}=39.86, P=0.022\right)$ but had no effect on partner choice $\left(H_{18}=20.91, P=0.284\right)$.

\section{DISCUSSION}

\subsection{Partner preference and incest avoidance}

The main outcome of this study is the absence of a mating preference between related and unrelated partners of $B$. terrestris under controlled conditions. In our study, the related pairs were represented mostly by brother-sister pairs, but the presence of nephew-aunt pairs could not be excluded. However, workers usually start to lay eggs late in the colony cycle, and considering the time required for development and achievement of sexual maturity they would rarely meet gynes of the same colony. As a consequence, the frequency of nephew-aunt pairs is expected to be much lower than that of brother-sister pairs.

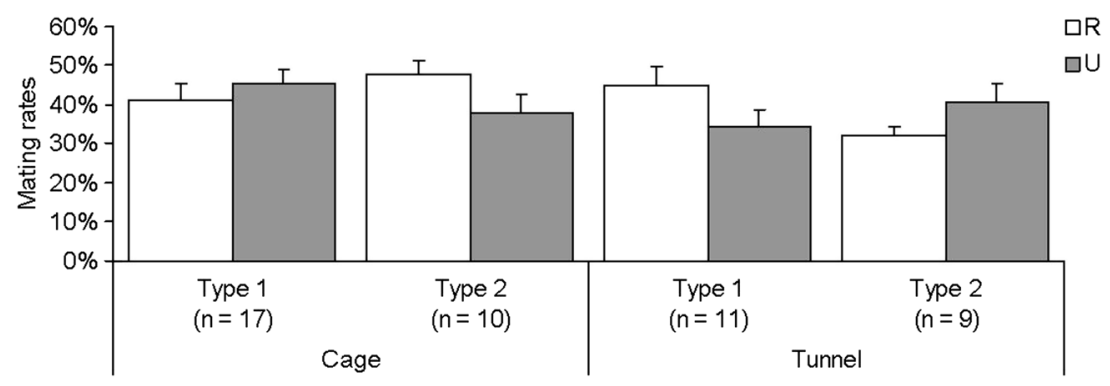

Figure 2. Mean ( \pm standard error) of related $(R)$ and unrelated $(U)$ matings rates in the two environments (cage and tunnel) and in the two mating types (I and II); $n$ number of mating sessions. 
Table II. Three-way ANOVA table of the effects of "Environment" (cage or tunnel), "Type" (I or II), and "Relationship" (related or unrelated) on mating latency

\begin{tabular}{llrr}
\hline & df & \multicolumn{1}{c}{ F } \\
\hline Environment & 1,401 & 151.727 & \multicolumn{2}{c}{$P$} \\
Type & 1,401 & 0.873 & 0.351 \\
Relationship & 1,401 & 5.879 & 0.016 \\
Environment*Type & 1,401 & 5.496 & 0.020 \\
Environment*Relationship & 1,401 & 1.222 & 0.270 \\
Type*Relationship & 1,401 & 1.896 & 0.169 \\
Environment*Type*Relationship & 1,401 & 1.118 & 0.291 \\
\hline
\end{tabular}

Previous research on the same species inferred the existence of a mating preference towards nonsiblings based on a shorter mating latency, interpreted as a higher mating propensity, compared to mating with siblings (Whitehorn et al. 2009b). However, a double choice mating test was never attempted with this species. In a matingchoice test similar to that of Whitehorn et al. (2009b), Foster (1992) found that gynes and males of $B$. frigidus and $B$. bifarius seemed to recognize nestmates of the opposite sex with a reduced inbreeding rate (although sibling matings were not totally avoided), while $B$. californicus and $B$. rufocintus did not show an inbreeding avoidance system. The author hypothesized that this variability among species could be linked to the different pre-copulatory behavior: $B$. californicus and $B$. rufocintus show a nest surveillance behavior to find females, but since they do not survey their own nest they do not need nestmate recognition cues; $B$. frigidus and $B$. bifarius, which have a patrolling behavior, can frequently encounter their sibling gynes and therefore they are advantaged by an incest avoiding system. Following this hypothesis, B . terrestris, which is a patrolling species, should have a similar nestmate avoidance system, but this is not consistent with our results. Male marking pheromones represent the main mating location mechanism in bumble bees. Despite this, there is no evidence about their use as an inbreeding avoidance system, since they have been demonstrated to be speciesand subspecies-specific (Rasmont et al. 2005; Coppée et al. 2008), and there are no studies about a possible nestmate specificity. In $B$. terrestris, a nestmate recognition system mediated by cuticular hydrocarbons is used to mark nest entrance and signal nest identity (Rottler et al. 2013), to prevent nest invasion by social parasites (Martin et al. 2010; Blacher et al. 2013), and to reduce the phenomenon of drifting workers (Zanette et al. 2014). Although insect cuticular hydrocarbons may also play important roles in short-distance and male-female contact communication (Kuo

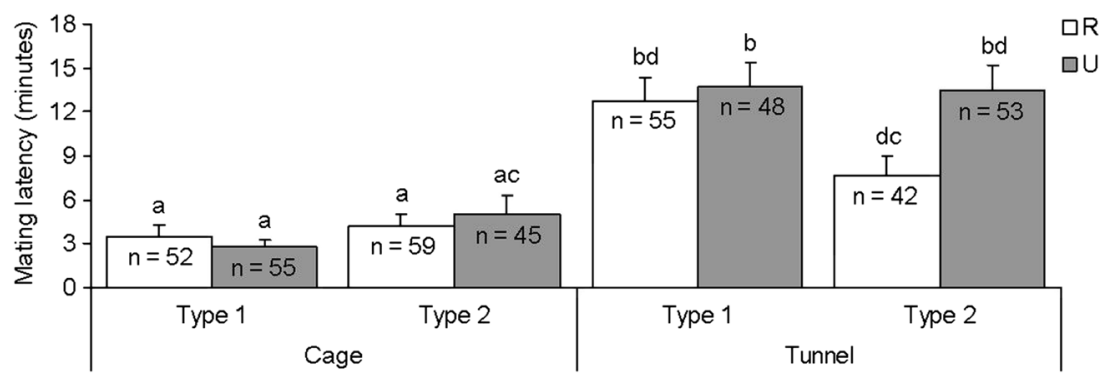

Figure 3. Mean ( \pm standard error) mating latency in related and unrelated matings in the two environments (cage and tunnel) and the two mating types (type 1 and type 2); $n$ number of mating pairs. Different letters denote statistical differences at $\alpha=0.05$. 
Table III. Three-way ANOVA table of the effects of "Environment" (cage or tunnel), "Type" (I or II), and "Relationship" (related or unrelated) on mating duration

\begin{tabular}{llrr}
\hline & df & \multicolumn{1}{c}{$F$} & \multicolumn{1}{c}{$P$} \\
\hline Environment & 1,395 & 170.212 & $<0.001$ \\
Type & 1,395 & 9.999 & 0.002 \\
Relationship & 1,395 & 1.272 & 0.260 \\
Environment*Type & 1,395 & 0.367 & 0.545 \\
Environment*Relationship & 1,395 & 0.067 & 0.796 \\
Type*Relationship & 1,395 & 0.059 & 0.809 \\
Environment*Type*Relationship & 1,395 & 5.565 & 0.019 \\
\hline
\end{tabular}

et al. 2012), no studies have been performed on bumble bees to detect their possible role in incest avoidance.

In our study, cage conditions have probably prevented all kind of odor discrimination, due to the tight confinement and high number of individuals. By contrast, in tunnel conditions, the flying area was wide enough for a recognition based on colony odors (cuticular recognition), allowing discrimination between nestmate and non-nestmate (Liebert et al. 2010). Even though we did not provide enough time to males to display patrolling and scent marking, the tunnel size allowed the performance of other pre-copulatory behaviors, such as queen approaching and inspecting by males and queen reaction to mating attempts (Bergman and Bergström 1997; Djegham et al. 1994; Whitehorn et al. 2009a). However, neither in cages nor in tunnels was any nestmate recognition system to avoid incest observed. Therefore, we hypothesize that $B$. terrestris does not use cuticular odor cues to prevent inbred mating, contrarily to what has been observed in some primitively eusocial bees (Smith and Ayasse 1987), in wasps (Liebert et al. 2010), and even in other insect species (Lihoreau et al. 2007; Lihoreau and Rivault 2010). Concerning scent marking performed by male bumble bees, further studies in larger tunnels could better clarify their possible role in kin recognition systems.

Amin et al. (2012) observed an influence of adult male characteristics, such as body weight and leg length, on mating rates. Although we did not directly evaluate the impact of these parameters, we observed an influence of male maternal colony on mating success, which in turn can determine these features. Contrarily, it seems that adult characteristics were not decisive in mating preference, since neither the maternal colony of gynes nor that of males influenced the choice among related and unrelated partners.

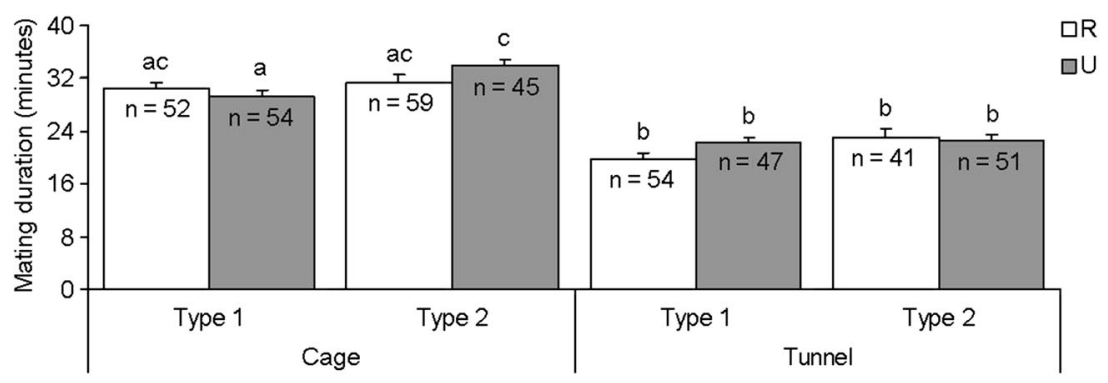

Figure 4. Mean ( \pm standard error) copulation duration in related and unrelated matings in the two environments (cage and tunnel) and the two mating types (type 1 and type 2); $n$ number of mating pairs. Different letters denote statistical differences at $\alpha=0.05$. 


\subsection{Mating phases duration}

The duration of copulation can be used by insects to adjust their mating investment in relation to their relatedness (Tabadkani et al. 2012). In bumble bees the long copulation duration is used by males to manipulate paternity in their own interests: it promotes effective sperm transfer and allows the application of the so-called "mating plug," a secretion produced by male accessory glands, which is applied to the female genital tract to prevent gynes from re-mating (Baer et al. 2000, 2001; Brown and Baer 2005). The mean values for copulation duration found in our study are consistent with previous reports for $B$. terrestris (Duvoisin et al. 1999), and the fact that no differences were found between inbred and outbred matings indicates the lack of a differential investment by males in response to gyne relatedness. The shorter copulation durations observed in tunnel conditions compared to the cage may be due to the different temperatures, which were about $20{ }^{\circ} \mathrm{C}$ in cage and up to $29^{\circ} \mathrm{C}$ in tunnel. This higher temperature is known to have a negative effect on mating success (Amin et al. 2010) and could have shortened copulation duration. Moreover, the mating duration was lower in type 2 than in type 1 matings, probably because of a higher competition in the latter mating type since both gynes and males derived from two different colonies.

Mating latency showed a different pattern between inbred and outbred matings, but in an opposite manner to what we expected. Whitehorn et al. (2009b) observed a longer latency in sibling than in non-sibling matings and interpreted this result as showing the existence in $B$. terrestris of a kin recognition system to avoid incest. On the contrary, we found a longer latency in outbred than in inbred matings. The most likely explanation for this unexpected result is that mating latency is not directly correlated to mating preference. Instead, mating latency could be influenced by other factors, such as the mating environment. In fact, we observed a shorter latency in cage matings than in tunnel matings, probably because in tighter spaces males are advantaged in finding gynes.

\subsection{Why not avoid incest?}

Our results strongly suggest that $B$. terrestris is a species in which inbred matings are not avoided, similarly to $B$. californicus and B. rufocinctus (Foster 1992). However, these two species show a pre-copulatory nest surveillance behavior which minimizes nestmate encounters, and $B$. californicus has a polyandric strategy that further reduces the risk of inbreeding. Conversely, B. terrestris is monandrous and has a patrolling pre-copulatory behavior which does not exclude inbred matings.

Since in some cases inbreeding implies serious fitness consequences in bumble bee colonies (Gerloff and Schmidt-Hempel 2005; Whitehorn et al. 2009a; Gosterit 2016), we would expect the existence of other mechanisms to avoid mating with close relatives, such as adult dispersal. Queen dispersal has not been studied in $B$. terrestris, although an indirect indication comes from its alien colonization of Tasmania, which was estimated at $300 \mathrm{~km}$ in about ten generations, indicating a high dispersal capacity (SchmidHempel et al. 2007). However, the particular context of this expansion is perhaps not representative of the dispersal process in the native range of the species. Recent studies showed that males of $B$. terrestris have a wide flight range, which can represent an effective strategy for increasing population size and reduce the risk of inbred mating (Kraus et al. 2009; Wolf et al. 2012). On the other hand, in Italy and other European countries, $B$. terrestris is the most abundant and widespread species (Rasmont et al. 2008). This high abundance acting as dilution factor in decreasing the possibility of mating with related individuals may be another key factor in incest avoidance.

Another factor to consider is that we used bumble bee colonies of commercial origin, which probably underwent several generations of artificial breeding. This could have eventually caused a selection toward a population which does not avoid incest, since enclosure conditions reduce the need to increase fitness. The possible contribution of this factor cannot be easily determined, because most mating studies found in literature have also been carried out on artificially reared populations.

Finally, the lack of an incest avoidance system in $B$. terrestris could not be interpreted as an 
evolutionary gap, since inbreeding could have positive effects on parents' fitness by increasing the representation of parental genes in future generations (Kokko and Ots 2006). In addition, retaining the possibility of inbred mating could represent a protection measure in the case of transitory isolation of the population. Together with the high inbreeding tolerance observed in $B$. terrestris, the possibility to perform indiscriminately inbred and outbred mating, exploiting the advantages of both strategies, can represent one of the key factors for the ecological success of this species.

\section{ACKNOWLEDGMENTS}

This work was carried out as part of the Life+ Project PP-ICON (Plant-Pollinator CONservation approach: a demonstrative proposal-LIFE09/NAT/IT000212), funded by the European Union. We thank Bioplanet s.c.a. for supplying the colonies, Mariachiara Zanichelli and Luca Galeotti for helping with bumble bee rearing, and Dr. Fabio Sgolastra for the precious help with statistics. We also thank the anonymous reviewers for comments on an early version of the manuscript.

\section{AUTHORS CONTRIBUTION}

GB and LB conceived this research and designed experiments; GB, NdM, AF, MG, and LB participated in the design and interpretation of the data; $\mathrm{GB}, \mathrm{LB}, \mathrm{NdM}$, and LZ carried out experiments and analysis; GB, NdM, AF, MG, LZ, and LB wrote the paper and participated in the revisions. All authors read and approved the final manuscript.Data availability

A summary of the data that support the findings of this study is available in Figures. 2, 3, and 4 and throughout the text. All other data are available from the corresponding author on reasonable request.

\section{COMPLIANCE WITH ETHICAL STANDARDS}

Conflict of interest The authors declare that they have no conflict of interest.

Aucune preuve d'un système d'évitement consanguin chez le bourdon Bombus terrestris
Bombus terrestris / consanguinité / évitement de l'inceste / reconnaissance de la famille / préférence d'accouplement

Keine Evidenz für ein Inzuchtvermeidungsprinzip bei der Hummel Bombus terrestris

Bombus terrestris / Inzucht / Inzestvermeidung / Verwandtschaftserkennung / Paarungspräferenz

\section{REFERENCES}

Amin, M. R., Kwon, Y. J., Suh, S. J. (2007) Photoperiodic influence on the body mass of bumblebee, Bombus terrestris and its copulation duration. J. Appl. Entomol. 131 (8), 537-541

Amin, M. R., Than, K. K., Kwon, Y. J. (2010) Mating status of bumblebees, Bombus terrestris (Hymenoptera: Apidae) with notes on ambient temperature, age and virginity. Appl. Entomol. Zool. 45 (3), 363-367

Amin, M. R., Bussière, L. F., Goulson, D. (2012) Effects of male age and size on mating success in the bumblebee Bombus terrestris . J. Insect. Behav. 25 (4), 362-374

Ayasse, M., Jarau, S. (2014) Chemical ecology of bumble bees. Annu. Rev. Entomol. 59, 299-319

Baer, B., Maile, R., Schmid-Hempel, P., Morgan, E. D., Jones, G. R. (2000) Chemistry of a mating plug in bumblebees. J. Chem. Ecol. 26 (8), 1869-1875

Baer, B., Morgan, E. D., Schmid-Hempel, P. (2001) A nonspecific fatty acid within the bumblebee mating plug prevents females from remating. Proc. Nat. Acad. Sci. 98 (7), 3926-3928

Baer, B. (2003) Bumblebees as model organisms to study male sexual selection in social insects. Behav. Ecol. Sociobiol. 54 (6), 521-533

Barrett, S. C. H., Charlesworth, D. (1991) Effects of a change in the level of inbreeding on the genetic load. Nature 352 (6335), 522-524

Beekman, M., Van Stratum, P., Veerman, A. (1999) Selection for non-diapause in the bumblebee Bombus terrestris, with notes on the effect of inbreeding. Entomol. Exp. Appl. 93 (1), 69-75

Bergman, P., Bergström, G. (1997) Scent marking, scent origin, and species specificity in male premating behavior of two Scandinavian bumblebees. J. ChemEcol. 23 (5), 1235-1251

Blacher, P., Boreggio, L., Leroy, C., Devienne, P., Châline, N., Chameron, S. (2013) Specific recognition of reproductive parasite workers by nestentrance guards in the bumble bee Bombus terrestris. Front. Zool. 10 (1), 74

Bogo, G., de Manincor, N., Fisogni, A., Galloni, M., Bortolotti, L. (2017) Effects of queen mating status, pre-diapause weight and pupae's sex on colony initiation in smallscale rearing of Bombus terrestris. Apidologie 1-10. 
Brown, M. J. F., Baer, B., Schmid-Hempel, R., SchmidHempel, P. (2002) Dynamics of multiple-mating in the bumble bee Bombus hypnorum. Insectes Soc. 49 (4), 315-319

Brown, M. J. F., Baer, B. (2005) The evolutionary significance of long copulation duration in bumble bees. Apidologie 36 (2), 157-167

Buckle, G. R., Greenberg, L. (1981) Nestmate recognition in sweat bees (Lasioglossum zephyrum): does an individual recognize its own odour or only odours of its nestmates?. Anim. Behav. 29 (3), 802-809

Charlesworth, D., Charlesworth, B. (1987) Inbreeding depression and its evolutionary consequences. Annu. Rev. Ecol. Syst. 18 (1), 237-268

Charlesworth, D., Willis, J. H. (2009) The genetics of inbreeding depression. Nat. Rev. Genet. 10 (11), 783-796

Coppée, A., Terzo, M., Valterova, I., Rasmont, P. (2008) Intraspecific variation of the cephalic labial gland secretions in Bombus terrestris (L.) (Hymenoptera: Apidae). Chem. Biodivers. 5 (12), 2654-2661

Darvill, B., Ellis, J. S., Lye, G. C., Goulson, D. (2006) Population structure and inbreeding in a rare and declining bumblebee, Bombus muscorum (Hymenoptera: Apidae). Mol. Ecol. 15 (3), 601-611

Darvill, B., Lepais, O., Woodall, L. C., Goulson, D. (2012) Triploid bumblebees indicate a direct cost of inbreeding in fragmented populations. Mol. Ecol. 21 (16), 3988-3995

Djegham, Y., Verhaeghe, J. C., Rasmont, P. (1994) Copulation of Bombus terrestris L. (Hymenoptera: Apidae) in captivity. J. Apic. Res. 33 (1), 15-20

Duchateau, M. J., Hoshiba, H., Velthuis, H. H. (1994) Diploid males in the bumble bee Bombus terrestris . Entomol. Exp. Appl. 71 (3), 263-269

Duchateau, M. J., Marien, J. (1995) Sexual biology of haploid and diploid males in the bumble bee Bombus terrestris . Insectes Soc. 42 (3), 255-266

Duvoisin, N., Baer, B., Schmid-Hempel, P. (1999) Sperm transfer and male competition in a bumblebee. Anim. Behav. 58 (4), 743-749

Ellis, J. S., Knight, M. E., Darvill, B., Goulson, D. (2006) Extremely low effective population sizes, genetic structuring and reduced genetic diversity in a threatened bumblebee species, Bombus sylvarum (Hymenoptera: Apidae). Mol. Ecol. 15 (14), 4375-4386

Estoup, A., Scholl, A., Pouvreau, A., Solignac, M. (1995) Monoandry and polyandry in bumble bees (Hymenoptera; Bombinae) as evidenced by highly variable microsatellites. Mol. Ecol. 4 (1), 89-94

Foster, R. L. (1992) Nestmate recognition as an inbreeding avoidance mechanism in bumble bees (Hymenoptera: Apidae). J. Kansas Entomol. Soc. 65 (3), 238-243

Gamboa, G. J., Reeve, H. K., Ferguson, I. D., Wacker, T. L. (1986) Nestmate recognition in social wasps: the origin and acquisition of recognition odours. Anim. Behav. 34 (3), 685-695
Gerloff, C. U., Ottmer, B. K., Schmid-Hempel, P. (2003) Effects of inbreeding on immune response and body size in a social insect, Bombus terrestris . Funct. Ecol. 17 (5), 582-589

Gerloff, C. U., Schmid-Hempel, P. (2005) Inbreeding depression and family variation in a social insect, Bombus terrestris (Hymenoptera: Apidae). Oikos 111 (1), 67-80

Getz, W. M., Smith, K. B. (1986) Honey bee kin recognition: learning self and nestmate phenotypes. Anim. Behav. 34 (6), 1617-1626

Goulson, D. (2010) Bumblebees: behaviour, ecology and conservation. Oxford University Press, New York.

Gosterit, A. (2016) Adverse effect of inbreeding on colony foundation success in bumblebee, Bombus terrestris (Hymenoptera: Apidae). Appl. Entomol. Zool. 51, 521-526

Gosterit, A., Gurel, F., (2016) Male remating and its influences on queen colony foundation success in the bumblebee, Bombus terrestris. Apidologie 47 (6), 828-834

Keller, L., Passera, L. (1993) Incest avoidance, fluctuating asymmetry, and the consequences of inbreeding in Iridomyrmex humilis, an ant with multiple queen colonies. Behav. Ecol. Sociobiol. 33 (3), 191-199

Keller, L., Ross, K. G. (1998) Selfish genes: a green beard in the red fire ant. Nature 394 (6693), 573-575

Kokko, H., Ots, I. (2006) When not to avoid inbreeding. Evol. 60 (3), 467-475

Kraus, F. B., Wolf, S., Moritz, R. F. A. (2009) Male flight distance and population substructure in the bumblebee Bombus terrestris. J. Anim. Ecol. 78 (1), 247-252

Kuo, T. H., Yew, J. Y., Fedina, T. Y., Dreisewerd, K., Dierick, H. A., Pletcher, S. D. (2012) Aging modulates cuticular hydrocarbons and sexual attractiveness in Drosophila melanogaster. J. Exp. Biol. 215 (5), 814-821

Kwon, Y. J., Amin, M. R., Suh, S. J. (2006) Mating propensity of Bombus terrestris reared in different photoperiodic regimes. Apidologie 37 (6), 679-686

Lacy, R. C., Petric, A., Warneke, M. (1993) Inbreeding and outbreeding in captive populations of wild animal species, in: Thornhill, N. W. (ed.) The natural history of inbreeding and outbreeding: theoretical and empirical perspectives. University of Chicago Press, Chicago, pp. 352-374

Liebert, A. E., Johnson, R. N., Switz, G. T., Starks, P. T. (2004) Triploid females and diploid males: underreported phenomena in Polistes wasps? Insectes Soc. 51 (3), 205-211

Liebert, A. E., Wilson-Rich, N., Johnson, C. E., Starks, P. T. (2010) Sexual interactions and nestmate recognition in invasive populations of Polistes dominulus wasps. Insectes Soc. 57 (4), 457-463

Lihoreau, M,, Zimmer, C., Rivault, C. (2007) Kin recognition and incest avoidance in a group-living insect. Behav. Ecol. 18 (5), 880-887 
Lihoreau, M., Rivault, C. (2010) German cockroach males maximize their inclusive fitness by avoiding mating with kin. Anim. Behav. 80 (2), 303-309

Martin, S. J., Carruthers, J. M., Williams, P. H., Drijfhout, F. P. (2010) Host specific social parasites (Psithyrus) indicate chemical recognition system in bumblebees. J. Chem. Ecol. 36 (8), 855-863

Pusey, A., Wolf, M. (1996) Inbreeding avoidance in animals. Trends Ecol. Evol. 11 (5), 201-206

Rasmont, P., Terzo, M., Aytekin, A. M., Hines, H., Urbanova, K., Cahlikova, L., Valterova, I. (2005) Cephalic secretions of the bumblebee subgenus Sibiricobombus Vogt suggest Bombus niveatus Kriechbaumer and Bombus vorticosus Gerstaecker are conspecific (Hymenoptera, Apidae, Bombus). Apidologie 36 (4), 571-84

Rasmont, P., Coppée, A., Michez, D., De Meulemeester, T. (2008) An overview of the Bombus terrestris (L. 1758) subspecies (Hymenoptera: Apidae). Ann. Soc. Entomol. Fr. 44 (2), 243-250

Ross, K. G., Fletcher, D. J. C. (1986) Diploid male production - a significant colony mortality factor in the fire ant Solenopsis invicta (Hymenoptera: Formicidae). Behav. Ecol. Sociobiol. 19 (4), 283-291

Rottler, A. M., Schulz, S., Ayasse, M. (2013) Wax lipids signal nest identity in bumblebee colonies. J. Chem. Ecol. 39 (1), 67-75

Sauter, A., Brown, M. J. F. (2001) To copulate or not? The importance of female status and behavioural variation in predicting copulation in a bumblebee. Anim. Behav. 62 (2), 221-226

Schmid-Hempel, R., Schmid-Hempel, P. (2000) Female mating frequencies in Bombus spp. from Central Europe. Insectes Soc. 47 (1), 36-41

Schmid-Hempel, P., Schmid-Hempel, R., Brunner, P. C., Seeman, O. D., Allen, G. R. (2007) Invasion success of the bumblebee, Bombus terrestris, despite a drastic genetic bottleneck. Heredity 99 (4), 414-422
Smith, B. H., Ayasse, M. (1987) Kin-based male mating preferences in two species of halictine bee. Behav. Ecol. Sociobiol. 20 (5), 313-318

Tabadkani, S. M., Nozari, J., Lihoreau, M. (2012) Inbreeding and the evolution of sociality in arthropods. Naturwissenschaften 99 (10), 779-788

Tasei, J. N., Moinard, C., Moreau, L., Himpens, B., Guyonnaud, S. (1998) Relationship between aging, mating and sperm production in captive Bombus terrestris. J. Apic. Res. 37 (2), 107-113

Van Wilgenburg, E., Driessen, G., Beukeboom, L. W. (2006) Single locus complementary sex determination in Hymenoptera: an "unintelligent" design. Front. Zool. 3 (1), 1

Whitehorn, P. R., Tinsley, M. C., Brown, M. J., Darvill, B., Goulson, D. (2009a) Impacts of inbreeding on bumblebee colony fitness under field conditions. BMC Evol. Biol. 9 (1), 152

Whitehorn, P. R., Tinsley, M. C., Goulson, D. (2009b) Kin recognition and inbreeding reluctance in bumblebees. Apidologie 40 (6), 627-633

Whitehorn, P. R., Tinsley, M. C., Brown, M. J., Darvill, B., Goulson, D. (2011) Genetic diversity, parasite prevalence and immunity in wild bumblebees. Proc. Roy. Soc. London B 278 (1709), 1195-1202

Williams, M. R., Abbott, I., Liddelow, G. L., Vellios, C., Wheeler, I. B., Mellican, A. E. (2001) Recovery of bird populations after clearfelling of tall open eucalypt forest in Western Australia. J Appl Ecol 38 (5), 910-920

Wolf, S., Toev, T., Moritz, R. L. V., Moritz, R. F. A. (2012) Spatial and temporal dynamics of the male effective population size in bumblebees (Hymenoptera: Apidae). Popul. Ecol. 54 (1), 115-124

Zanette, L. R. S., Miller, S. D. L., Faria, C. M. A., LopezVaamonde, C. L., Bourke, A. F. G. (2014) Bumble bee workers drift to conspecific nests at field scales. Ecol. Entomol. 39 (3), 347-354 